\title{
Global risks and population policy
}

\section{ZIPAR Policy Brief}

October 2018

Marko Kovic, Adrian Rauchfleisch, and Christian Caspar 


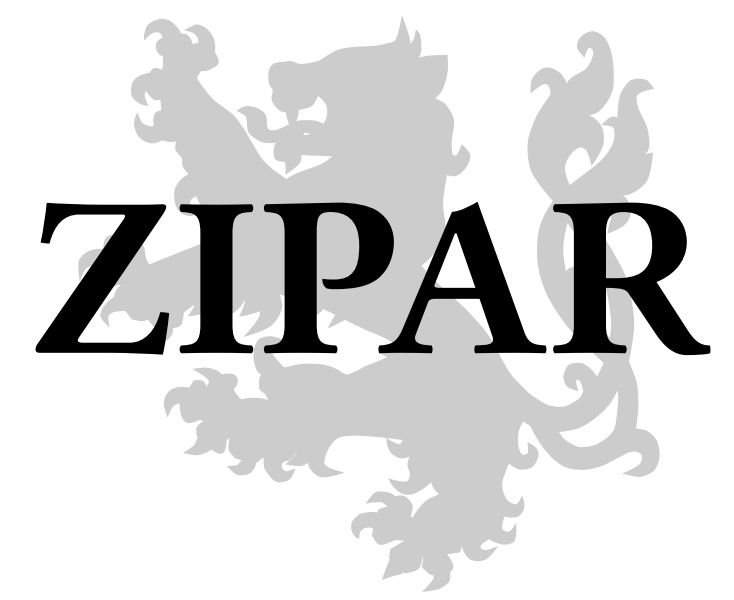

\section{About ZIPAR}

The Zurich Institute of Public Affairs Research is devoted to identifying and addressing the major challenges for humankind in the short-term, in the mediumterm, and in the long-term future. ZIPAR is an independent nonprofit think tank based in Zurich, Switzerland.

\section{Recommended citation}

Marko Kovic, Adrian Rauchfleisch, and Christian Caspar (2018): Global risks and population policy. ZIPAR Policy Brief. Zurich, Switzerland.

\section{Copyright}

This document is licensed under a Creative Commons Attribution-NonCommercialNoDerivatives 4.0 International license. You can freely distribute this document and reference it in other works. For any questions about copyright, feel free to contact the author (marko.kovic@zipar.org). 


\begin{abstract}
Population policy in the sense of the active and targeted reduction of future life years is a potential mitigation strategy for global risks. We argue that even though population policy is almost certainly effective in principle, it is not necessarily practically viable or desirable, for three reasons. First, in order to be as effective as possible, population policy would necessarily (also) target Western developed nations, but debates on population policy, paradoxically, seem to focus on developing countries. Second, reducing future life years is potentially a great moral burden because it means reducing the total amount of future happiness; systematically preventing people from coming into existence is a difficult moral problem. Third, population policy as a risk mitigation strategy is somewhat self-defeating because the successful mitigation of some risk by means of population policy reduces the very utility of mitigating that risk. These three problem areas do not make population policy categorically unacceptable, but any use of population policy for the mitigation of global risks is in need of strong and evidence-based justification. Given that the resources available for mitigating global risks are limited, we believe that they should be used on more promising risk mitigation approaches and strategies.
\end{abstract}




\section{Contents}

1 Introduction: More people, more (and greater) risks 5

\begin{tabular}{|lll|}
\hline 2 & The problems of population policy as a risk mitigation strategy & 6
\end{tabular}

2.1 What population and whose life years? The question of effectiveness 6

2.2 The moral burden of reducing future life years . . . . . . 7

2.3 Race to the bottom, or: The diminishing utility of population policy 8

3 Conclusions 9

3.1 Policy recommendations . . . . . . . . . . . . . . . 9 9

$4 \quad$ Epilogue: Individual autonomy vs. population policy 10 


\section{Introduction: More people, more (and greater) risks}

The global human population is currently greater than at any point in the history of humankind, and it is likely to continue increasing to at least the end of the 21st century [1, 2]. Even though the growth of the human population can generally be seen, from a purely biological perspective, as a development indicative of something positive (if a species increases in numbers, something is going well for that species), population growth can also be cause for concern. There are three reasons for this.

First, and least importantly, more people in the world can result in more migration, and migration is a delicate political issue in developed countries. Even though there is evidence that immigration into developed countries has increased in recent years [3], global migration flows are probably not challenging in a fundamental way, because migration is a fairly tractable problem (The practical issue with migration might stem from a lack of international agreements and cooperation rather than from the problem of migration in and of itself [4].).

Second, and more importantly, population growth can result in overpopulation, as numerous influential works have been warning since the 1970ies [ [5, 6, 7 , 8]. The overpopulation risk means that too large a population runs the risk of exceeding the Earth's ecological carrying capacity [9]. That would result in an unsustainable use of resources, with potentially catastrophic short- to medium-term consequences, such as sudden and violent civilizational collapse. The overpopulation risk is intuitively plausible, but not necessarily inevitably true, because it generally rests on the assumption of ceteris paribus population growth: The way we use resources is the same, but there are more people; therefore, the mere addition of people creates a problem. In reality, however, resource use is not always the same, but contingent on technology: Technological progress can, in principle, outpace the risk of overpopulation. More people do not necessarily create more ecological strain if the technology we use for extracting, transforming, and using resources improves.

Third, however, technological progress itself is not risk-free. Technological progress can and does help us increase happiness and reduce suffering in the world, but it also brings about new kinds of anthropogenic risks. More specifically, technological progress tends to increase both the number and the gravity of risks that humans create; so much so that we are today facing more existential risks (risks that are threatening all of humankind [10]) than ever before [11]. Population growth can causally increase the pace of technological innovation (for example, through more brainpower dedicated to research and development), and it can increase the probability that people and organizations will accidentally or 
deliberately misuse technology [12].

If we care about global catastrophic risks (as we should [13]), and if we believe that policy has a big role to play in managing risks and preventing bad outcomes (as it does [14]), and, furthermore, if population growth seems to coincide with the growth of risks both in number and gravity, then a conclusion seems obvious: We should design policy that limits population growth in order to mitigate global risks. This line of policy-thinking is not new, but it has become more prominent in recent years. One area in which population policy is being pondered as a risk mitigation strategy is climate change [15, 16, 17].

\section{The problems of population policy as a risk mit- igation strategy}

The basic premise of population policy as a risk mitigation strategy is almost certainly true: Fewer people in existence (or, more specifically: fewer life years in existence) almost certainly leads to a reduction of global risks. However, even though the basic premise of population policy is true, population policy is not necessarily a practically or morally desirable risk mitigation strategy. There are at least three reasons for this.

\subsection{What population and whose life years? The question of effectiveness}

Reducing future life years might seem like an abstract idea, but it is, at the same time, very much a practical problem. If we want to reduce future life years, then we need to decide, at the very least, whose future life years we want to reduce. This means that we need to define one or several target populations, and we need to decide the specific kind of future life years that are to be reduced. Typical target populations for population policy are populations that are currently experiencing above-average population growth. For example, in the context of climate change, the population on the African continent is typically regarded as a suitable target for population policy by means of reducing population growth [16]. However, it is not at all clear whether that is a suitable starting point for population policy. For example, per capita greenhouse gas emissions are massively higher in Western countries [18], so reducing future life years in Western countries would have a much greater impact than reducing future life years in developing countries.

The difficulty with selecting target populations for the reduction of future life years is that we might not make these kinds of decisions in an entirely rational manner. Various cognitive biases [19] very likely play a role in determining 
target populations for reducing future life years. Our intuitive moral circles are heavily biased and essentially irrational demarcations [20,21] that can negatively impact the effectiveness of population policy considerations. For example, the average proponent of population policy in the West is unlikely to be willing to reduce their own future life years, or that of their (potential) children, or that of their (potential) children's (potential) children. Such an intuitive position is understandable - after all, we intuitively want ourselves and those we love to live long and happy lives; reducing life years goes against that intuition. In contrast, reducing the future life years of people who live (or will live) far away and who are different from us is a much easier choice. But it might be an ineffective one.

\subsection{The moral burden of reducing future life years}

Reducing future life years is obviously morally problematic if we are seeking to actively reduce future life years of people who currently exist. For example, abolishing vaccines would be a highly effective intervention for reducing life years in existing people, since vaccines have a large positive effect on life span 22 , 23]. But reducing future life years in such a manner would probably be deemed grotesquely immoral, if not psychopathic.

However, reducing future life years is usually not an intuitive moral concern if the life years that are to be reduced belong to people who do not exist yet. In other words and more specifically: If we reduce life years by preventing some people from coming into existence, then we might intuitively conclude that no harm is done - because there is no one to do the harm to. This kind of moral intuition is sometimes referred to as the person-affecting view [24], whereby a population-level action is only bad if it is bad for someone; for a living human being who is affected by the action.

The person-affecting-view has, however, some caveats because it allows for outcomes that are actually difficult to justify morally. Perhaps the most critical problem of the person-affecting-view is the so-called non-identity problem [25]. If we accept a person-affecting view, then bringing into existence even severely unhappy and suffering people and life years is morally acceptable because no previously existing person was actually harmed by that and because the unhappy and suffering people are, arguably, better off existing than not existing. On the other hand, the person-affecting view does also not regard bringing happy and fulfilled people and life years into existence as morally desirable, because even such "positive" potential future life years do not affect people who already exist. If our general moral goal is to maximize happiness and welfare (this is the basic tenet of utilitarianism [26, 27]), then the person-affecting view can be problematic.

If we accept the moral premise that future life years matter because they can increase happiness, however, we are confronted with another problem, the 
so-called repugnant conclusion [28]. The repugnant conclusion is the conclusion that a population with more people can be more desirable even if the average happiness in a bigger population is lower than it would be in a smaller population. That is counter-intuitive and potentially repugnant because it follows that even a population with very low average happiness and welfare, a metaphorical hell on Earth, could still be desirable because the total amount of happiness is greater than in a much smaller population with much higher average happiness, but with lower total happiness. To a large degree, slightly lower average happiness in favor of greater total happiness seems perfectly acceptable, but determining the threshold at which greater total happiness to the detriment of average happiness is not desirable any longer is enormously difficult and requires precise empirical work.

The non-identity problem and the repugnant conclusion are not, of course, arguments that make any kind of population policy impermissible. They are, however, counter-intuitive conclusions that demonstrate the moral burden of actively reducing future life years by means of population policy: Preventing people from coming into existence is a much greater moral problem than we typically realize through the lens of our ad hoc person-affecting moral intuition. Even though we might intuitively believe that reducing future life years is morally trivial if no existing people are affected, reducing future life years of non-existing people is a thorny moral problem. Perhaps the only consistent moral position in which reducing future life years is universally acceptable is strong anti-natalism [29] which is premised on the argument that non-existence is always preferable to existence because no amount of happiness can outweigh the inevitable suffering that accompanies existence. We suspect that most proponents of population policy do not adhere to the anti-natalist moral framework.

In summary, the moral burden of population policy consists of the potential moral damage done through the reduction of future happiness. Rather than treating the moral burden of population policy en passant as a triviality, as we are prone to doing intuitively, specific policy population proposals should provide precise (empirical) justifications in terms of their moral impact.

\subsection{Race to the bottom, or: The diminishing utility of pop- ulation policy}

In the introduction, we argue that the basic premise of population policy as a risk mitigation strategy is almost certainly true: Reducing future life years almost certainly results in a reduction of global risks. From this premise, we can draw a trivial, yet important conclusion: The greatest reduction in global risks can be achieved by reducing future life years to zero. Should that be the ultimate goal of 
population policy as a risk mitigation strategy?

No, of course not: The very reason why we care about global risks is because of how many humans are affected by them. Reducing how many humans there are in order to reduce risks is akin to amputating an arm in order to reduce the risk of breaking it. Proponents of population policy presumably believe that the goal is not to reduce future life years to zero, but rather to reduce them enough so that the global risk or risks in question decrease to a more manageable level. But even such a gradualist interpretation of population policy can be baffling. For example, if a country decided to reduce its population by $20 \%$ in order to reduce traffic deaths by $20 \%$, that would probably be an effective strategy - but it would be a curious course of action, since there would be fewer people to benefit from the reduced risk.

That problem lies at the core of the issue: Population policy as a risk mitigation strategy means that we are mitigating a risk, but we are, at the same time, reducing the benefit of mitigating that risk. That is not the kind of risk mitigation strategy that we usually try to employ because it is of an inherently contradictory nature. When we mitigate some risk, we do so because we expect our risk mitigation efforts to bear some specific benefit. A risk mitigation strategy whose utility diminishes the more successful it is is fundamentally flawed.

\section{Conclusions}

\subsection{Policy recommendations}

Humankind is facing more numerous and more consequential risks than ever before. Many of those risks are man-made, and they correlate to some degree with the size of the human population. In principle, those risks can be mitigated by reducing the size of the human population or, more specifically, by reducing how many life years there will be in the future. Even though this kind of risk mitigation works in principle, we regard it as dubious in practice for three major reasons: Population policy as a risk mitigation strategy is not necessarily effective; it is morally problematic; and it diminishes the very benefits we seek to maximize by engaging in risk mitigation. We believe that these three problems make population policy a generally dubious risk mitigation strategy that needs to, at the very least, be explicitly justified in terms of the three problem areas we identified.

In addition to the three problems of population policy, the dimension of practical feasibility and governance is also important policy-wise. A good example of the practical feasibility of risk mitigation strategies is climate change. Historically, concerted global action on climate change has been difficult to enact and therefore at best moderately effective [30]. In view of the fact that relatively simple, morally 
unambiguous and highly effective climate change risk mitigation strategies such as a carbon tax [31, 32] have not been implemented yet, implementing any kind of large-scale population policy seems unrealistic from a practical point of view. In addition to the three problem areas of population policy we outline above, population policy endeavors are therefore unlikely to be practically feasible in climate change risk mitigation. The governance problem of population policy in the context of climate change is likely to exist in the context of any global risk, not just climate change risk.

In light of these limitations and problems, we recommend against employing population policy as a risk mitigation strategy. On a conceptual level, its effectiveness, morality, and utility are uncertain. On a practical level, there is no straightforward way of implementing large-scale population policy. The resources needed for dubious and uncertain population policy efforts can probably be put to more effective risk mitigating use.

\section{Epilogue: Individual autonomy vs. population policy}

A critical or cautious stance towards population policy might raise the question of whether and how individual decisions about future life years ought to be regarded. If the strategic top-down, policy-induced reduction of future life years can be problematic, is the same true for individual decisions about reducing future life years? If we disregard cases that are outright morally and legally wrong (reducing life years by, for example, actively killing people or actively withholding lifeextending medical care), there are two major cases of reduction of life years in the purview of individual autonomy: Suicide and family planning.

Suicide, the act of intentionally causing one's own death, has a strong correlation with physical and mental suffering [33, 34], so the act of committing suicide can hardly be evaluated on moral grounds as a rational act for reducing future life years. People who commit suicide do so because they are suffering, not because they want to reduce future life years as a risk mitigation strategy.

Family planning means actively deciding whether, how many, and what kinds of children parents want to bring into existence. From the point of view of autonomy, family planning is a liberating trend or tool set, especially for women. Even though the availability of family planning services and technology generally correlates with lower birth rates, individual family planning is not the same as top-down population policy, primarily because most individuals do not consider their family planning to be a global risk mitigation strategy, but rather a personal biographical choice. In other words: Individual family planning cannot be a 
(good or bad) risk mitigation strategy if it is not intended to be a risk mitigation strategy by the individuals who engage in family planning. Individual family planning, however, does have moral implications outside the context of global risk mitigation, since the basic moral questions about creating or reducing future life years are essentially the same on an individual and on an aggregate top-down level. The scale of the decisions, on the other hand, is not: The moral impact of population policy is much greater than the moral impact of an act of individual family planning.

Population policy as a risk mitigation strategy is usually fundamentally different from individual autonomy and individual decision-making about future life years: When we make decisions about future life years as individuals, we rarely do so within the context of global risk mitigation. Accordingly, criticism of top-down, large scale population policy does not translate into criticism of individual autonomy. 


\section{References}

[1] Max Roser and Esteban Ortiz-Ospina. World Population Growth. 2017 (cit. on p. 5).

[2] Patrick Gerland, Adrian E. Raftery, Hana Ševčíková, Nan Li, Danan Gu, Thomas Spoorenberg, Leontine Alkema, Bailey K. Fosdick, Jennifer Chunn, Nevena Lalic, Guiomar Bay, Thomas Buettner, Gerhard K. Heilig, and John Wilmoth. "World population stabilization unlikely this century". In: Science 346.6206 (2014), pp. 234-237. Dor: 10 . 1126 / science . 1257469 (cit. on p.5).

[3] Guy J. Abel and Nikola Sander. "Quantifying Global International Migration Flows”. In: Science 343.6178 (2014), pp. 1520-1522. Dor: 10 . 1126 /science. 1248676 (cit. on p. 5).

[4] Marco Scipioni. "Failing forward in EU migration policy? EU integration after the 2015 asylum and migration crisis". In: Journal of European Public Policy 25.9 (2018), pp. 1357-1375. Dor: 10 . 1080/13501763 . 2017 . 1 325920 (cit. on p. 5).

[5] Paul R. Ehrlich. The population bomb. New York: Ballantine Books, 1971. ISBN: 978-0-345-02171-7 (cit. on p. 5).

[6] Paul R. Ehrlich and Anne H. Ehrlich. The Population Explosion. New York: Touchstone Books, 1991. ISBN: 978-0-671-73294-3 (cit. on p. 5).

[7] Philip Cafaro and Eileen Crist. Life on the Brink: Environmentalists Confront Overpopulation. University of Georgia Press, 2012. ISBN: 978-0-8203-4048-7 (cit. on p.5).

[8] Alan Weisman. Countdown: Our Last, Best Hope for a Future on Earth? New York: Little, Brown and Company, 2013. ISBN: 978-0-316-09775-8 (cit. on p. 5).

[9] Kenneth Arrow, Bert Bolin, Robert Costanza, Partha Dasgupta, Carl Folke, C. S. Holling, Bengt-Owe Jansson, Simon Levin, Karl-Göran Mäler, Charles Perrings, and David Pimentel. "Economic growth, carrying capacity, and the environment”. In: Ecological Economics 15.2 (1995), pp. 91-95. DOI: 10.1016/0921-8009(95)00059-3 (cit. on p.5).

[10] Marko Kovic. Why does nobody care about existential risks? 2017 (cit. on p. 5).

[11] John G. Sotos. "Biotechnology and the lifetime of technical civilizations". In: arXiv:1709.01149 [physics] (2017) (cit. on p. 5).

[12] Phil Torres. "Agential Risks: A Comprehensive Introduction”. In: Journal of Evolution \& Technology 26.2 (2016), pp. 31-47 (cit. on p. 6). 
[13] Nick Bostrom. "Existential Risk Prevention as Global Priority". In: Global Policy 4.1 (2013), pp. 15-31. DOI: 10.1111/1758-5899. 12002 (cit. on p. 6).

[14] Marko Kovic. The future of humankind will be determined by policy. 2018 (cit. on p. 6).

[15] Judith Stephenson, Karen Newman, and Susannah Mayhew. "Population dynamics and climate change: what are the links?" In: fournal of Public Health 32.2 (2010), pp. 150-156. Dor: 10 . 1093 / pubmed / fdq038 (cit. on p.6).

[16] John Bongaarts and Brian C. O'Neill. "Global warming policy: Is population left out in the cold?” In: Science 361.6403 (2018), pp. 650-652. Dor: 10 . 11 $26 /$ science aat 8680 (cit. on p. 6).

[17] Helen Kopnina and Haydn Washington. "Discussing why population growth is still ignored or denied". In: Chinese fournal of Population Resources and Environment 14.2 (2016), pp. 133-143. DOI: 10 . 1080/10042857 . 201 6.1149296 (cit. on p. 6).

[18] Climate analysis indicators tool: WRI's climate data explorer. Washington, D.C., 2014 (cit. on p. 6).

[19] Daniel Kahneman. "Maps of Bounded Rationality: Psychology for Behavioral Economics”. In: The American Economic Review 93.5 (2003), pp. 14491475 (cit. on p. 6).

[20] Simon M. Laham. "Expanding the moral circle: Inclusion and exclusion mindsets and the circle of moral regard". In: Fournal of Experimental Social Psychology 45.1 (2009), pp. 250-253. DOI: $10.1016 /$ j . jesp. 2008 . 0 8.012 (cit. on p. 7).

[21] Americus Reed and Karl F. Aquino. "Moral identity and the expanding circle of moral regard toward out-groups." In: Journal of Personality and Social Psychology 84.6 (2003), pp. 1270-1286. DOI: 10 . $1037 / 0022-35$ 14.84.6.1270 (cit. on p.7).

[22] FE Andre, R Booy, HL Bock, J Clemens, SK Datta, TJ John, BW Lee, S Lolekha, H Peltola, TA Ruff, M Santosham, and HJ Schmitt. "Vaccination greatly reduces disease, disability, death and inequity worldwide". In: Bulletin of the World Health Organization 86.2 (2008) (cit. on p. 7).

[23] Jenifer Ehreth. "The global value of vaccination”. In: Vaccine. Vaccines and Immunisation 2003. Based on the Third World Congress on Vaccines and Immunisation 21.7-8 (2003), pp. 596-600. DOI: 10 . 1016/S0264-410 $\mathrm{X}(02) 00623-0$ (cit. on p.7). 
[24] Nils Holtug. "Person-Affecting Moralities". In: The Repugnant Conclusion: Essays on Population Ethics. Ed. by Torbjörn Tännsjö and Jesper Ryberg. Library Of Ethics And Applied Philosophy. Dordrecht: Springer Netherlands, 2004, pp. 129-161. ISBN: 978-1-4020-2473-3. DOI: 10 . 1007/978-1-40 20-2473-3_8 (cit. on p.7).

[25] M. A. Roberts. "The Nonidentity Problem”. In: The Stanford Encyclopedia of Philosophy. Ed. by Edward N. Zalta. Metaphysics Research Lab, Stanford University, 2015 (cit. on p. 7).

[26] John Stuart Mill. Utilitarianism. Parker, Son and Bourn, 1863 (cit. on p.7).

[27] Krister Bykvist. Utilitarianism: A Guide for the Perplexed. Bloomsbury Publishing, 2009. ISBN: 978-1-4411-5866-6 (cit. on p.7).

[28] Derek Parfit. "Overpopulation and the Quality of Life”. In: The Repugnant Conclusion: Essays on Population Ethics. Ed. by Torbjörn Tännsjö and Jesper Ryberg. Library Of Ethics And Applied Philosophy. Dordrecht: Springer Netherlands, 2004, pp. 7-22. ISBN: 978-1-4020-2473-3. DOI: 10 . $1007 / 97$ 8-1-4020-2473-3_2 (cit. on p. 8).

[29] David Benatar. Better Never to Have Been: The Harm of Coming into Existence. Oxford: Oxford University Press, 2008. IsBN: 978-0-19-954926-9 (cit. on p. 8).

[30] Joyeeta Gupta. "A history of international climate change policy”. In: Wiley Interdisciplinary Reviews: Climate Change 1.5 (2010), pp. 636-653. DOI: 10 $.1002 /$ wcc .67 (cit. on p.9).

[31] Reuven S. Avi-Yonah and David M. Uhlmann. "Combating Global Climate Change: Why a Carbon Tax is a Better Response to Global Warming than Cap and Trade". In: Stanford Environmental Law fournal 28 (2009), p. 3 (cit. on p. 10).

[32] M. Burke, M. Craxton, C. D. Kolstad, C. Onda, H. Allcott, E. Baker, L. Barrage, R. Carson, K. Gillingham, J. Graff-Zivin, M. Greenstone, S. Hallegatte, W. M. Hanemann, G. Heal, S. Hsiang, B. Jones, D. L. Kelly, R. Kopp, M. Kotchen, R. Mendelsohn, K. Meng, G. Metcalf, J. Moreno-Cruz, R. Pindyck, S. Rose, I. Rudik, J. Stock, and R. S. J. Tol. "Opportunities for advances in climate change economics”. In: Science 352.6283 (2016), pp. 292-293. Dor: 10.112 6/science. aad9634 (cit. on p. 10).

[33] J. T. O. Cavanagh, A. J. Carson, M. Sharpe, and S. M. Lawrie. "Psychological autopsy studies of suicide: a systematic review". In: Psychological Medicine 33.3 (2003), pp. 395-405. Dor: 10 . $1017 /$ S 0033291702006943 (cit. on $\mathrm{p} \cdot 10$. 
[34] Matthew K. Nock, Guilherme Borges, Evelyn J. Bromet, Jordi Alonso, Matthias Angermeyer, Annette Beautrais, Ronny Bruffaerts, Wai Tat Chiu, Giovanni de Girolamo, Semyon Gluzman, Ron de Graaf, Oye Gureje, Josep Maria Haro, Yueqin Huang, Elie Karam, Ronald C. Kessler, Jean Pierre Lepine, Daphna Levinson, Maria Elena Medina-Mora, Yutaka Ono, José Posada-Villa, and David Williams. "Cross-national prevalence and risk factors for suicidal ideation, plans and attempts”. In: The British fournal of Psychiatry 192.2 (2008), pp. 98-105. DOI: $10.1192 /$ bjp.bp . 107.04 0113 (cit. on p. 10. 